\title{
Particulate Matters Levels in Subway Tunnels and Cabins
}

\author{
Wonseog Jeong ${ }^{1,2}$, Yongil Lee ${ }^{1,2}$, Kyomin Choi ${ }^{1,2}$, Duckshin Park ${ }^{1, *}$ \\ ${ }^{1}$ Transportation Environmental Research Team, Korea Railroad Research Institute, Uiwang City, Republic of Korea \\ ${ }^{2}$ Department of Mechanical Engineering, Sung Kyun Kwan University, Suwon City, Republic of Korea
}

\section{Email address:}

dspark@krri.re.kr (D. Park)

*Corresponding author

\section{To cite this article:}

Wonseog Jeong, Yongil Lee, Kyomin Choi, Duckshin Park. Particulate Matters Levels in Subway Tunnels and Cabins. International Journal of Environmental Monitoring and Analysis. Vol. 4, No. 3, 2016, pp. 89-93. doi: 10.11648/j.ijema.20160403.14

Received: March 24, 2016; Accepted: April 5, 2016; Published: May 4, 2016

\begin{abstract}
This research aims to discern the characteristics of $\mathrm{PM}_{10}$ concentrations measured in subway cabins, tunnels and outdoors at the Seoul Metropolitan subways. $\mathrm{PM}_{10}$ concentrations in cabins were found between the range of 45.3 and $101.9 \mu \mathrm{g} / \mathrm{m}^{3}$, and in tunnels the ranges were between 155.3 and $230.6 \mu \mathrm{g} / \mathrm{m}^{3} . \mathrm{PM}_{10}$ concentrations in cabins and tunnels during rush hours were $16.5 \%$ and $3.8 \%$ respectively higher than non-rush hours. Fine particles were higher than that of coarse particles both in subway cabins and tunnels.
\end{abstract}

Keywords: Indoor Air Quality, PM10, Subway Cabin, Tunnel

\section{Introduction}

From the time its first line began operations in 1974, the Seoul Metropolitan Subway has been expanding to connect the entire city area. In 2011 a total of 2.4 billion people had used the subway from lines 1 to 8 , with about 6.66 million. The subway takes up a $35.2 \%$ share of total transportation usage. As additional subway lines are planned for other metropolitan cities, the number of passengers using subways nationwide is expected to grow significantly (Seoul, 2009).

Air quality in subway cabins is comparatively worse than in the indoor spaces of other public buildings at ground level. Therefore, passenger health becomes an increasing concern as they are exposed to such pollutants over a prolonged period of time (Kim et al., 2006). $\mathrm{PM}_{10}$ is a major pollutant in subway stations that is known to be generated from various factors such as subway train operation, passenger movement, and the inflow of outside air through the ventilation system. Epidemiological studies show that exposure to $\mathrm{PM}_{10}$ is highly hazardous to the body, since it rises the sensible pollution level and along with it is the possible occurrence of disease and death rates. As $\mathrm{PM}_{10}$ concentrations measured in subways are generally higher and more toxic than those in the air (Nieuwenhuijsen et al., 2007), they play a major role in deteriorating subway air quality and as such require proper control.
Many studies have measured $\mathrm{PM}_{10}$ concentrations in the subway of major cities such as Beijing (Li et al., 2006), Hong Kong (Chan et al., 2002), Prague (Branis, 2006), London (Seaton et al., 2005) and New York (Chillrud et al., 2004). Other studies have measured $\mathrm{PM}_{10}$ levels in Seoul subway stations and tunnels (Park and Ha, 2008; Park et al., 2004; Lee et al., 2010).

In this study, we measured the $\mathrm{PM}_{10}$ concentrations of the Seoul Metropolitan subway lines from 5 to 8 using the light scattering method in order to observe $\mathrm{PM}_{10}$ characteristics in subway cabins and tunnels. We also compared the $\mathrm{PM}_{10}$ concentrations of outside air with those inside the cabins and tunnels, and analyzed the significance.

\section{Research Methods}

We used the light scattering method for this study as it is easy to control and enables continuous measurement. In this research, we measured the $\mathrm{PM}_{10}$ concentration with Sky-OPC (Grimm 1.108). For measurement, the dust spectrometer divides $\mathrm{PM}_{10}$ in the air into 32 channels by size at about a $1.2 \ell / \mathrm{min}$ flow rate. The device can store data at 6 -second intervals.

The measurement was conducted outdoors, in the cabins and tunnels of the Seoul Metropolitan subway lines 5 to 8 during rush and non-rush hours. Details of the measured lines 
are described in table 1 (Seoul Metropolitan Rapid Transit Corporation, 2011). Line 5 has a $52.3 \mathrm{~km}$ in length and transported 296.5 million passenger traffic.

The measurement was carried out at the center of the subway cabins to minimize the influence of outside air. Measurement in the tunnels was conducted by putting tubes out through the windows to suction the ambient air. The sampling places for each individual measurement are shown in figure 1. SPSS ver. 13.0 was used to analyze the data.

Table 1. Seoul subway lines from 5 to 8.

\begin{tabular}{llll}
\hline $\begin{array}{l}\text { Line } \\
\text { No. }\end{array}$ & Section & $\begin{array}{l}\text { No. of passengers } \\
(\mathbf{1 , 0 0 0 / y e a r )}\end{array}$ & $\begin{array}{l}\text { Operation } \\
\text { extension }(\mathbf{k m})\end{array}$ \\
\hline 5 & Banghwa - Sangil-dong, & 296,458 & 52.3 \\
6 & Macheon & 177,622 & 35.1 \\
7 & Eungam - Bonghwasan & 315,541 & 46.9 \\
8 & Jangam- Onsu & 84,404 & 17.7 \\
\hline
\end{tabular}
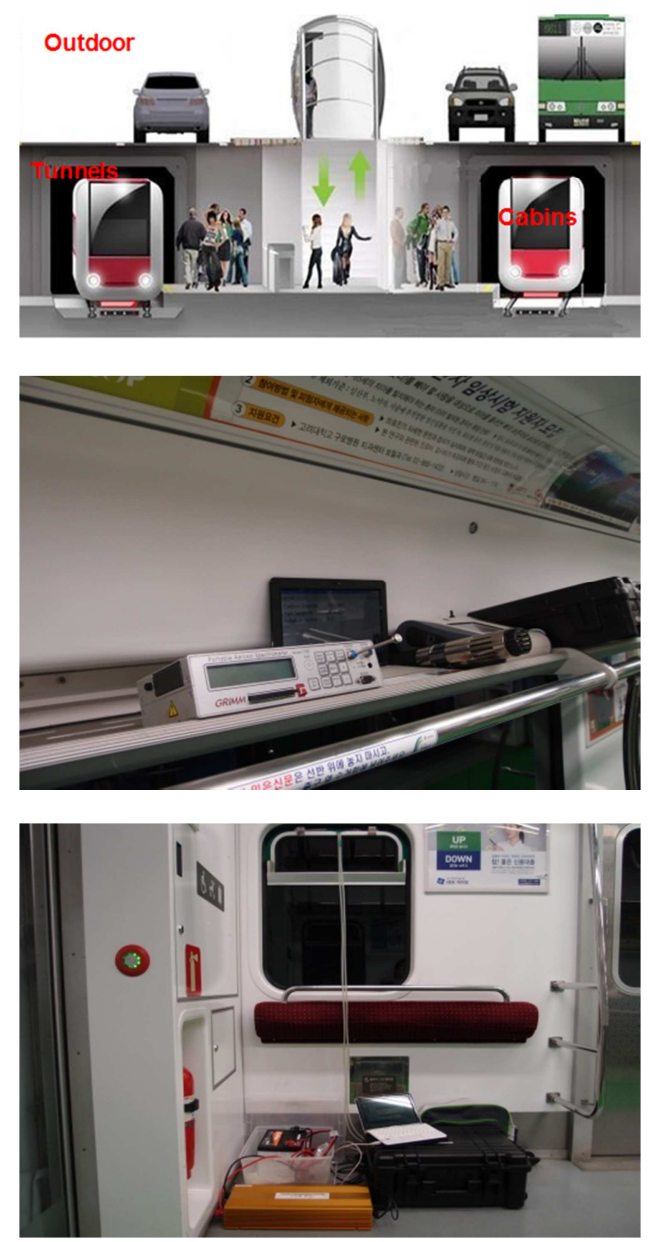

Figure 1. Measurement places and apparatuses in subway.

\section{Results and Discussion}

\subsection{PM ${ }_{10}$ Concentrations in Subway Cabins}

Table 2 shows the results of $\mathrm{PM}_{10}$ concentrations in cabins of lines 5 to 8 . The average $\mathrm{PM}_{10}$ concentration was higher during the rush hours than non-rush hours in all lines. During the rush hours, each line showed $115.8 \mu \mathrm{g} / \mathrm{m}^{3}, 83.1 \mu \mathrm{g} / \mathrm{m}^{3}$,
$90.7 \mu \mathrm{g} / \mathrm{m}^{3}$, and $66.0 \mu \mathrm{g} / \mathrm{m}^{3}$ for lines $5,6,7$ and 8 , respectively. Line 5 showed the highest level and line 8 as the lowest. Most of the results were lower than $150 \mu \mathrm{g} / \mathrm{m}^{3}$, which is the level of guidelines for public transportations in Korea with the exemptions of lines 5 and 7. In terms of hourly measurement results by line, $\mathrm{PM}_{10}$ concentrations during rush hours were $22.2 \%, 35.3 \%, 12.4 \%$, and $23.1 \%$, higher than during non-rush hours, for lines 5, 6, 7 and 8 , respectively. This is probably because particles carried in by the number of passengers and suspended particles by the operation of trains during rush hours affect the $\mathrm{PM}_{10}$ concentration in cabins. Brains et al. (2005) and Fromme et al. (2007) reported that the indoor $\mathrm{PM}_{10}$ concentration was greatly affected by the activities of the people in a room. In a passenger cabin, there is an increase in passenger activity when the passengers enter and exit the cabin. However, quantitative measures to observe passenger activities inside a cabin were not available for this study.

Table 2. $P M_{10}$ concentration in subway cabins in line 5.

\begin{tabular}{lllll}
\hline Line 5 & & $\mathbf{1}^{\text {st }}$ & $\mathbf{2}^{\text {nd }}$ & Total \\
\hline \multirow{4}{*}{ Rush hours } & Ave. & 101.9 & 132.8 & 115.8 \\
& SD & 15.3 & 22.2 & 24.2 \\
& Max. & 163.3 & 182.8 & 182.8 \\
\multirow{4}{*}{ Non rush hours } & Min. & 73.9 & 75.5 & 73.9 \\
& Ave. & 93.1 & 96.5 & 94.8 \\
& SD & 13.5 & 14.0 & 13.8 \\
& Max. & 138.4 & 150.2 & 68.0 \\
& Min. & 68.0 & 73.7 & 150.2 \\
\hline
\end{tabular}

Table 3. $P M_{10}$ concentration in subway cabins in line 6.

\begin{tabular}{lllll}
\hline Line 6 & & $\mathbf{1}^{\text {st }}$ & $\mathbf{2}^{\text {nd }}$ & Total \\
\hline \multirow{4}{*}{ Rush hours } & Ave. & 70.7 & 95.5 & 83.1 \\
& SD & 12.2 & 14.1 & 18.1 \\
& Max. & 95.0 & 126.4 & 126.4 \\
& Min. & 32.6 & 40.1 & 32.6 \\
Non rush hours & Ave. & 45.8 & 77.0 & 61.4 \\
& SD & 3.9 & 14.6 & 18.9 \\
& Max. & 62.1 & 159.9 & 159.9 \\
\hline
\end{tabular}

Table 4. $P M_{10}$ concentration in subway cabins in line 7.

\begin{tabular}{lllll}
\hline Line 7 & & $\mathbf{1}^{\text {st }}$ & $\mathbf{2}^{\text {nd }}$ & Total \\
\hline \multirow{4}{*}{ Rush hours } & Ave. & 75.3 & 106.0 & 90.7 \\
& SD & 8.9 & 20.4 & 22.0 \\
& Max. & 113.9 & 164.7 & 164.7 \\
& Min. & 51.4 & 49.3 & 49.3 \\
Non rush hours & Ave. & 76.8 & 84.5 & 80.7 \\
& SD & 9.0 & 14.7 & 12.8 \\
& Max. & 113.2 & 133.3 & 133.3 \\
& Min. & 63.9 & 56.9 & 56.9 \\
\hline
\end{tabular}

Table 5. $P M_{10}$ concentration in subway cabins in line 8.

\begin{tabular}{lllll}
\hline Line 8 & & $\mathbf{1}^{\text {st }}$ & $\mathbf{2}^{\text {nd }}$ & Total \\
\hline \multirow{4}{*}{ Rush hours } & Ave. & 66.4 & 65.6 & 66.0 \\
& SD & 4.6 & 14.4 & 10.6 \\
& Max. & 80.9 & 109.6 & 109.6 \\
& Min. & 56.9 & 27.2 & 27.2 \\
Non rush hours & Ave. & 53.2 & 54.1 & 53.6 \\
& SD & 6.2 & 6.1 & 6.2 \\
& Max. & 67.2 & 68.3 & 68.3 \\
& Min. & 41.6 & 42.7 & 41.6 \\
\hline
\end{tabular}




\section{2. $P M_{10}$ Concentration in Subway Tunnels}

Table 6. $P M_{10}$ concentration in subway passenger tunnels (line 5).

\begin{tabular}{lllll}
\hline Line 5 & & $\mathbf{1}^{\text {st }}$ Measurement & $\mathbf{2}^{\text {nd }}$ Measurement & Total \\
\hline \multirow{3}{*}{ Rush } & Ave. & 327.0 & 383.1 & 355.6 \\
hours & SD & 56.2 & 63.0 & 66.0 \\
& Max. & 615.2 & 558.2 & 615.2 \\
& Min. & 215.5 & 255.6 & 215.5 \\
Non & Ave. & 161.1 & 232.3 & 195.8 \\
rush & SD & 22.3 & 51.9 & 53.2 \\
hours & Max. & 226.8 & 437.9 & 437.9 \\
& Min. & 114.1 & 113.6 & 113.6 \\
& Min. & 193.6 & 72.8 & 72.8 \\
\hline
\end{tabular}

Table 7. PM 10 concentration in subway passenger tunnels (line 6).

\begin{tabular}{|c|c|c|c|c|}
\hline Line 6 & & $1^{\text {st }}$ Measurement & $2^{\text {nd }}$ Measurement & Total \\
\hline \multirow{4}{*}{$\begin{array}{l}\text { Rush } \\
\text { hours }\end{array}$} & Ave. & 187.7 & 229.0 & 206.9 \\
\hline & SD & 21.5 & 39.2 & 37.2 \\
\hline & Max. & 255.9 & 353.5 & 353.5 \\
\hline & Min. & 128.4 & 105.3 & 105.3 \\
\hline \multirow{4}{*}{$\begin{array}{l}\text { Non rush } \\
\text { hours }\end{array}$} & Ave. & 181.8 & 189.4 & 185.6 \\
\hline & SD & 18.5 & 38.8 & 30.6 \\
\hline & Max. & 247.2 & 408.3 & 408.3 \\
\hline & Min. & 136.9 & 102.3 & 102.3 \\
\hline
\end{tabular}

Table 8. $P M_{10}$ concentration in subway passenger tunnels (line 7).

\begin{tabular}{lllll}
\hline Line 7 & & $\mathbf{1}^{\text {st }}$ Measurement & $\mathbf{2}^{\text {nd }}$ Measurement & Total \\
\hline \multirow{3}{*}{ Rush } & Ave. & 224.9 & 260.2 & 242.7 \\
hours & SD & 30.7 & 72.9 & 58.8 \\
& Max. & 372.8 & 543.6 & 543.6 \\
& Min. & 172.4 & 97.2 & 97.2 \\
Non & Ave. & 230.6 & 165.2 & 197.7 \\
rush & SD & 21.7 & 63.2 & 57.5 \\
hours & Max. & 342.8 & 555.8 & 555.8 \\
\hline
\end{tabular}

Tables 6 to 9 show the results of $\mathrm{PM}_{10}$ concentration measurement in tunnels on lines 5 to $8 . \mathrm{PM}_{10}$ concentrations were higher during the rush hours than non-rush hours for all lines. During rush hours, $355.6 \mu \mathrm{g} / \mathrm{m}^{3}, 206.9 \mu \mathrm{g} / \mathrm{m}^{3}$, $242.7 \mu \mathrm{g} / \mathrm{m}^{3}$, and $148.6 \mu \mathrm{g} / \mathrm{m}^{3}$ were for lines $5,6,7$ and 8 respectively, with line 5 having the highest level and line 8 got the lowest. In terms of hourly measurement results by line, $\mathrm{PM}_{10}$ concentrations during rush hours were $81.6 \%$, $11.5 \%, 22.8 \%$, and $13.9 \%$ higher than during non-rush hours for lines 5, 6, 7 and 8, respectively.

Table 9. $P M_{10}$ concentration in subway passenger tunnels (line 8).

\begin{tabular}{lllll}
\hline Line 8 & & $\mathbf{1}^{\text {st }}$ Measurement & $\mathbf{2}^{\text {nd }}$ Measurement & Total \\
\hline \multirow{3}{*}{ Rush } & Ave. & 184.8 & 110.5 & 148.6 \\
hours & SD & 22.6 & 24.4 & 44.0 \\
& Max. & 250.1 & 178.4 & 250.1 \\
& Min. & 145.4 & 55.5 & 55.5 \\
Non & Ave. & 158.8 & 106.0 & 130.5 \\
rush & SD & 26.3 & 20.1 & 33.4 \\
hours & Max. & 204.4 & 146.7 & 204.4 \\
& Min. & 115.8 & 68.4 & 68.4 \\
\hline
\end{tabular}

\subsection{Correlations of $P M_{10}$ Concentrations}

Figure 2 shows $\mathrm{PM}_{10}$ concentrations in subway cabins and tunnels of lines 5 to 8 . For all subway lines, the $\mathrm{PM}_{10}$ concentrations were higher in tunnels than in cabins and it also shows that is higher during rush hours than non-rush hours. The concentration in cabins of line 5 , which shows the highest concentration in tunnels, was also high in comparing the cabins between the other lines, while line 8, the lowest concentration in tunnels, was also low in cabins. This is probably because the $\mathrm{PM}_{10}$ concentration in subway cabins affects $\mathrm{PM}_{10}$ concentration in tunnels. An outdoor PM10 concentration was measured for three places, at the same time it was measured in subway cabins and tunnels.

We selected station $G$ of line 5 to measure $\mathrm{PM}_{10}$ concentration in tunnels, subways and outdoors, simultaneously. Though Station G is not a transfer station, it is widely used at ordinary times.

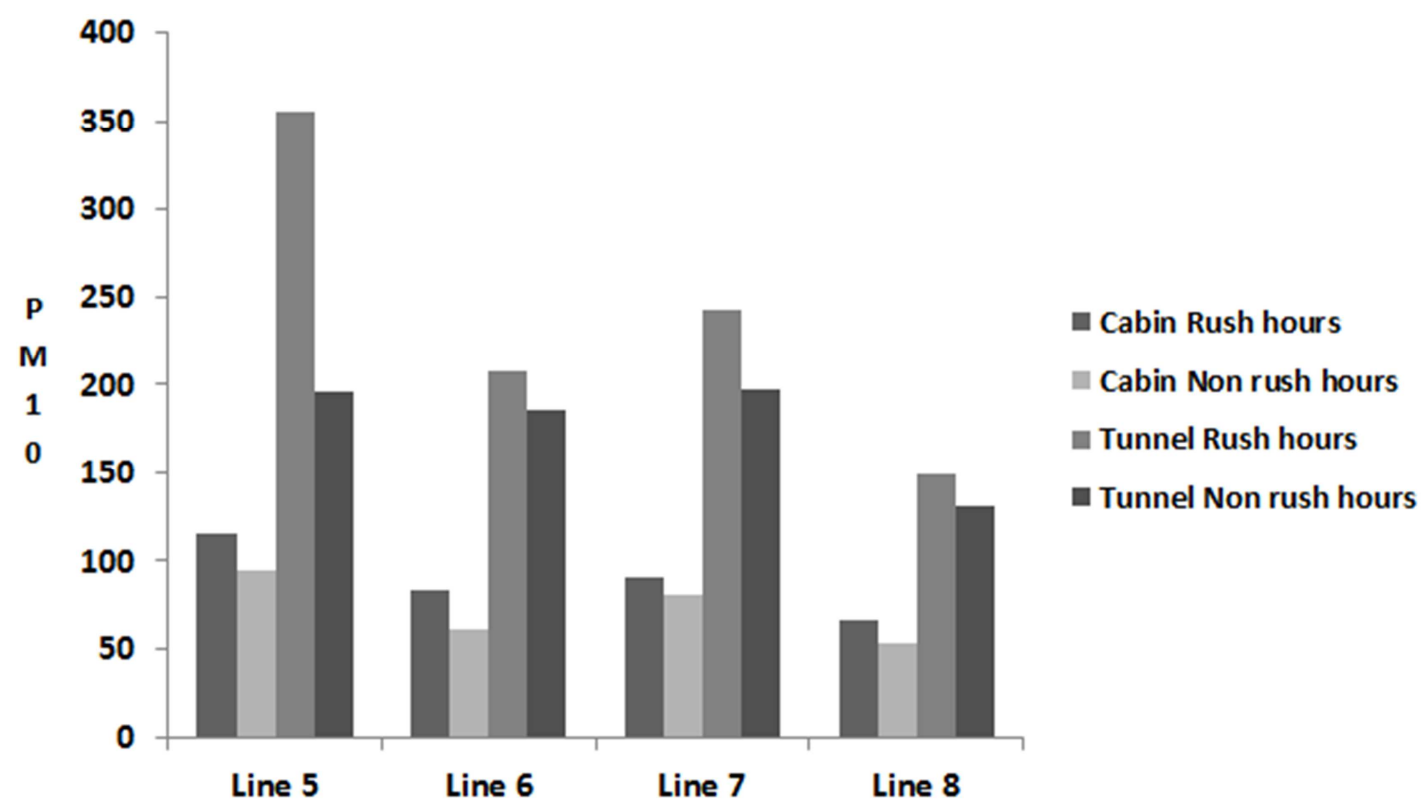

Figure 2. PM 10 concentrations in subway cabins and tunnels. 
Figure 3 shows the concentration distribution of $\mathrm{PM}_{10}$ for Station G. The concentrations of fine particles are higher than that of coarse particles in the three places (outdoors, subway tunnels and cabins). Figure 4 shows the concentration distribution of $\mathrm{PM}_{10}$ by size at the three places. In the case of outdoors, the concentration is highest when the particle sizes are between $0.35 \mu \mathrm{m}$ and $4.5 \mu \mathrm{m}$. For tunnels, the concentrations are at its highest level when the particle size is between $0.25 \mu \mathrm{m}$ and $0.35 \mu \mathrm{m}$, and at $1.6 \mu \mathrm{m}$. Subway cabins show peak concentration at $0.35,2.5$ and $6.5 \mu \mathrm{m}$, demonstrating that $\mathrm{PM}_{10}$ concentrations are affected by outside air and tunnels.

According to the PMF study for subway cabins and tunnels the $\mathrm{PM}_{10}$ consisted of $52.5 \%$ inorganic components, $10.2 \%$ anions, and $37.3 \%$ other materials including cations, organic and inorganic carbons, and other unmeasured components. The iron content was the highest, generally accounting for $10-70 \%$ of the $\mathrm{PM}_{10}$ concentration. The fours sources identified by the PMF model were soil and road dust, railroad-related pollution sources, secondary nitrate, and $\mathrm{Cl}^{-}$ factor mixed with secondary sulfates and the sources accounted for $27.2 \%, 47.6 \%, 16.2 \%$, and $9.1 \%$ of the $\mathrm{PM}_{10}$, respectively (Park et al., 2014; Park et al., 2012).

Thus, it is required to install ventilation facilities to block the $\mathrm{PM}_{10}$ brought in from tunnels and reduce the $\mathrm{PM}_{10}$ carried in by the passengers.

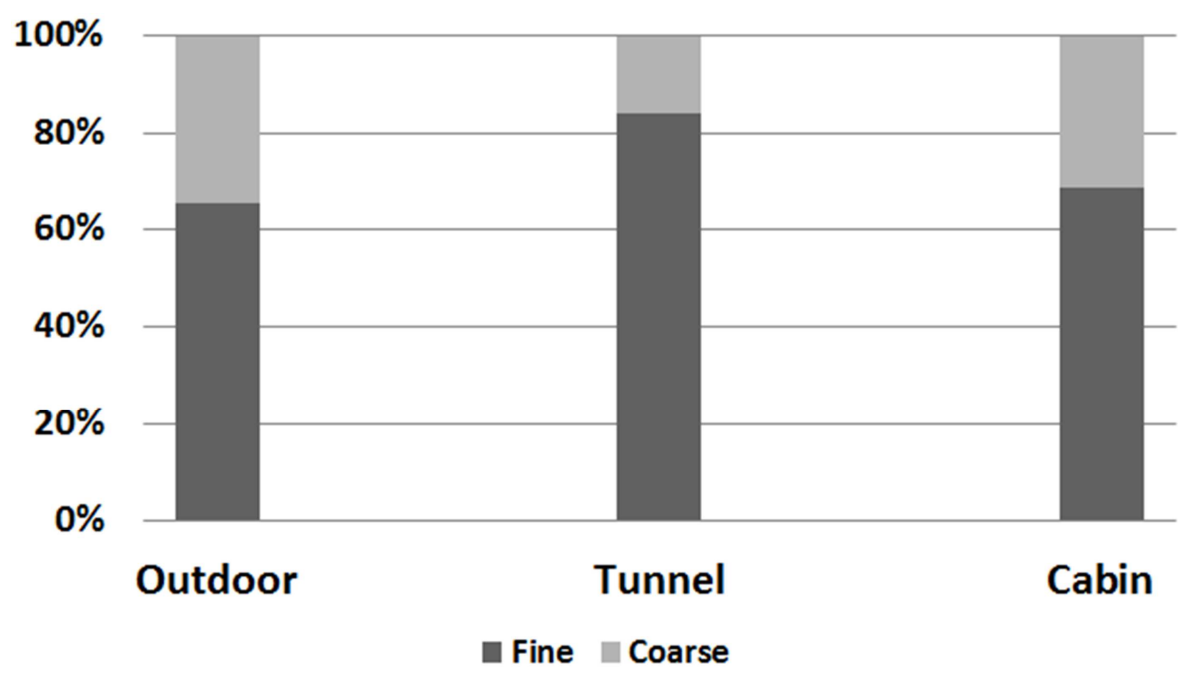

Figure 3. PM size distributions in station $G$.

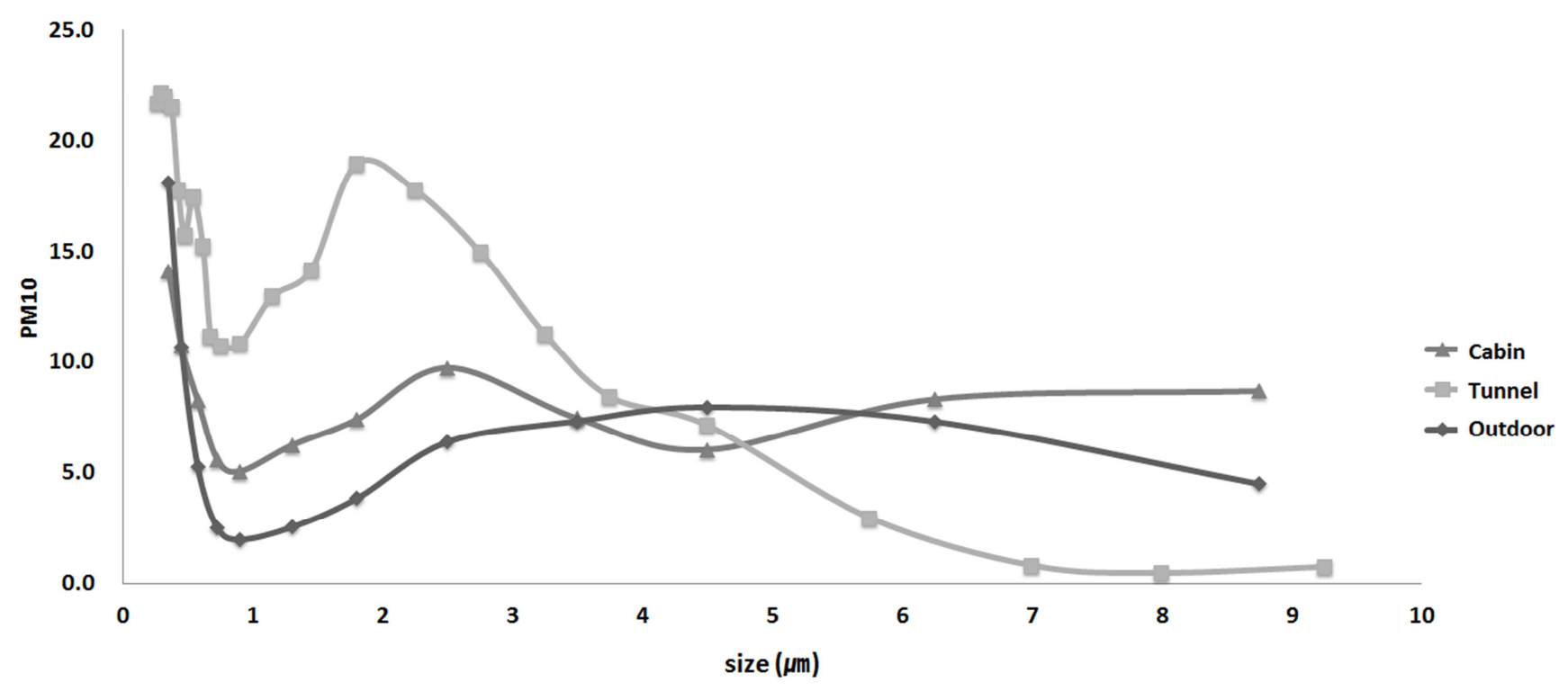

Figure 4. PM size distributions in subway cabins and tunnels.

\section{Conclusion}

In this study, we measured the PM concentrations of the Seoul metropolitan subways. Sky-OPC was used in order to characterize PM concentrations in subway cabins and tunnels. We also compared the PM concentrations of outside air with those in cabins, tunnels, and analyzed the significance.

The average PM concentration in cabins of lines 5 to 8 is significantly higher during rush hours than non-rush hours 
among all the lines used. In addition, the average PM concentrations in tunnels of lines 5 to 8 are also relatively higher during rush hours than non-rush hours for all lines.

Outdoor $\mathrm{PM}_{10}$ concentration was measured for three points at the same time it was measured in cabins and tunnels. The concentrations of fine particles are higher than that of coarse particles in three places (outdoors, tunnels and cabins). Subway cabins show the peak concentrations at $0.35,2.5$ and $6.5 \mu \mathrm{m}$, demonstrating that PM concentrations are affected by outside air and tunnels. Thus, as it has been mentioned, it is essential to install ventilation facilities to block the $\mathrm{PM}_{10}$ brought in from tunnels and reduce the PM carried in by passengers.

\section{Acknowledgement}

The work described in this manuscript was supported by the research grant of Railway Technology Research Project (14RTRP-B081249-01) from the Ministry of Land, Infrastructure and Transport.

\section{References}

[1] Brains, M. (2006) The contribution of ambient sources to particulate pollution in spaces and trains of the Prague underground transport system, Atmospheric Environment, 40, 348-356.

[2] Chan, L. Y., W. L. Lau, S. C. Lee, and C. Y. Chan (2002) Commuter exposure to particulate matter in public transportation modes in Hong Kong, Atmospheric Environment, 36, 3363-3373.

[3] Chillrud, S. N., D. Epstein, J. M. Ross, S. N. Sax, D. Pederson, J. D. Spengler, and P. L. Kinney (2004) Elevated airborne exposures of teenagers to manganese, chromium, and iron from steel dust and New York City's subway system, Environmental Science and Technology, 38, 732-737.

[4] Fromme, H., D. Twardella, S. Dietrich, D. Heitmann, R. Schierl, B. Liebl, and H. Ruden (2007) Particulate matter in the indoor air of classrooms-exploratory results from Munich and surrounding area, Atmospheric Environment, 41, 854-866.
[5] Kim, K. Y., J. B. Park, C. N. Kim, and K. J. Lee (2006) Assessment of airborne bacteria and particulate matters distributed in Seoul metropolitan subway stations, Kor. J. of Env. Health., 32(4), 254-261.

[6] Lee, T. J., J. S. Kim, S. D. Kim, and D. S. Kim (2010) A comparative study on $\mathrm{PM}_{10}$ source contribution in a Seoul metropolitan subway station before/after installing platform screen doors, Journal of Korean Society for Atmospheric Environment, 26(5), 543-553.

[7] Li, T. T., Y. H. Bai, Z. R. Liu, J. F. Liu, G. S. Zhang, and J. L. $\mathrm{Li}$ (2006) Air quality in passenger cars of the ground railway transit system Beijing, China, Science of Total Environment, 367, 89-95.

[8] Nieuwenjuisen, M. J., J. E. Gomez-Perales, and R. N. Colvile (2007) Levels of particulate air pollution, its elemental composition, determinants and health effects in metro systems, Atmospheric Environment, 41, 7995-8006.

[9] Park, D. S., Y. M. Cho, C. K. Lee, and B.H. Park (2004) Study on the quality of air inside tunnel, Journal of Korean Society for Atmospheric Environment, 38, 363-364.

[10] Park, D. S., M. S. Oh, Y. H. Yoon, E. Y. Park, and K. Lee (2012) Source identification of PM10 pollution in subway passenger cabins using positive matrix factorization, Atmospheric Environment, 49, 180-185.

[11] Park, D. S., T. J. Lee, D. Y. Hwang, W. S. Jung, Y. I. Lee, K. C. Cho, D. S. Kim, and K. Lee (2014) Identification of the sources of PM10 in a subway tunnel using positive matrix factorization, Journal of the Air \& Waste Management Association, 64(12), 1361-1368.

[12] Park, D. U. and K. C. Ha (2008) Characteristics of $\mathrm{PM}_{10}$, $\mathrm{PM}_{2.5}, \mathrm{CO}_{2}$ and $\mathrm{CO}$ monitored in interiors and platforms of subway train in Seoul, Korea, Environment International, 34(5), 629-634.

[13] Seaton, A., J. Cherrie, M. Dennekamp, K. Donaldson, J. F. Hurley, and C. L. Tran (2005) The London underground: dust and hazards to health, Occupational and Environmental Medicine, 62, 355-362.

[14] Seoul (2009) Http://stat.seoul/go.kr

[15] Seoul Metropolitan Rapid Transit Corporation (2011), http://www.smrt.co.kr 